\title{
Leitura e produção escrita de contos maravilhosos por uma perspectiva crítica
}

\author{
Reading and production written of wonderful accounts by a critical \\ perspective
}

https://doi.org/10.34112/2317-0972a2020V38n8op29-43

\section{Viviane Dinês de Oliveira Ribeiro Bartho ${ }^{1}$}

Resumo: Este trabalho é um relato de experiência realizada em uma escola de ensino básico envolvendo alunos dessa escola e alunos de graduação em Letras que participavam do PIBID $^{2}$. Relatam-se procedimentos de elaboração e desenvolvimento de um projeto de leitura e escrita do gênero discursivo "contos maravilhosos", orientado por mim, que, na ocasião, lecionava nas duas instituições envolvidas: a de ensino básico e superior. Apresentam-se sequências didáticas do projeto, até as etapas finais de confecção de um livro de contos maravilhosos modernos. O objetivo em relação aos alunos do ensino superior era o desenvolvimento de habilidades relacionadas à formação docente; e para os alunos do ensino básico era o desenvolvimento de habilidades de leitura crítica e produção escrita. O relato ancora-se em conceitos de língua, linguagem e gênero discursivo segundo a perspectiva bakhtiniana (2006, 2003); a concepção de ensino é baseada em Paulo Freire (2018); o planejamento de sequências didáticas em Tápias-Oliveira (2015) e em Dolz, Noverraz e Scheneuwly

1. Instituto Federal de São Paulo, Campos do Jordão, São Paulo, Brasil.

2. PIBID - Programa Institucional de Bolsa de Iniciação à Docência. "O programa oferece bolsas de iniciação à docência aos alunos de cursos presenciais que se dediquem ao estágio nas escolas públicas e que, quando graduados, se comprometam com o exercício do magistério na rede pública. O objetivo é antecipar o vínculo entre os futuros mestres e as salas de aula da rede pública. Com essa iniciativa, o Pibid faz uma articulação entre a educação superior (por meio das licenciaturas), a escola e os sistemas estaduais e municipais" (informações coletadas do site http://portal.mec.gov.br/pibid. Acesso em: o7 jan 2019). 
(2004). Resultados apontam para os benefícios da interação entre alunos de diferentes níveis de formação por meio de projetos didáticos, além de contribuições de programas institucionais como o PIBID para a formação docente.

Palavras-chave: PIBID de língua portuguesa; sequências didáticas de leitura e escrita; gênero discursivo conto maravilhoso.

ABSTRACT: This work is an experience report held in a basic school that involves the school and graduate students in PIBID. The procedures for the elaboration of a project of reading and writing of the discursive genre are described "wonderful tales", oriented by me, that, at the time, the basic education and a higher education. It presents didactic sequences of the project, until the final stages of making a book of wonderful modern short stories. The objective for higher education students was the development of skills related to teacher training; and for elementary school students was the development of critical reading and writing skills. The report is anchored in concepts of language, language and discursive genre according to the Bakhtinian perspective (2006, 2003; a conception about education based in Paulo Freire (2018); the planning of didactic sequences in Tápias-Oliveira (2015) and in Dolz, Noverraz and Scheneuwly (2004). Results pointed out to the benefits of the change between the students of different levels of training to the means of didactic projects, in addition to the contributions of institutional programs like the PIBID for a teacher training. KeYwords: PIBID of Portuguese language; didactic sequences of reading and writing; discursive genre tale wonderful.

\section{INTRODUÇÃO}

O presente trabalho consiste em um relato de experiência que vivenciei como professora de português do Ensino Fundamental II de uma escola municipal do interior do estado de São Paulo e como supervisora selecionada pelo Programa Institucional de Bolsa de Iniciação à Docência - PIBID para orientar um grupo de seis graduandos-bolsistas que, por coincidência, eram meus alunos no curso de Letras de uma universidade da mesma cidade, onde eu também lecionava, àquela época.

Os bolsistas eram encaminhados às escolas e aos professores que os acompanhariam a fim de que fosse definida a rotina de atividades desenvolvidas no semestre. Era solicitado aos supervisores que, além de observação de aulas, os bolsistas pudessem participar de regência de aulas, auxílio em projetos, elaboração de materiais didáticos, aplicação de exercícios, correção de textos e quaisquer outras atividades que fizessem 
parte do dia a dia da escola e da sala de aula de língua materna, uma vez que a ideia era proporcionar oportunidades de aprimoramento na formação docente dos estagiários.

Primeiramente, os bolsistas designados à minha supervisão passaram alguns dias observando a rotina da escola municipal e das turmas de $6^{\circ}$ ano para as quais eu lecionava na ocasião. Em seguida, apresentei a eles o conteúdo planejado para ser trabalhado nos próximos dias com os alunos, a saber, o gênero discursivo conto maravilhoso, conteúdo este previsto no planejamento anual para a referida série da rede de ensino municipal. A ideia era propor aos estagiários do PIBID o desenvolvimento com os alunos de $6^{\circ}$ ano de um projeto de leitura e produção escrita do gênero a ser introduzido. Eles, pela primeira vez, assumiriam aulas, supervisionados por mim, que ficaria em sala para qualquer auxílio necessário. Ao final de cada aula lecionada, seria dado um retorno aos estagiários, indicando-lhes pontos fortes e pontos a serem revistos sobre os trabalhos realizados.

A singularidade em relação ao conteúdo programado para a série, estabelecido pela secretaria de educação municipal, era o fato de que trabalharíamos o gênero conto maravilhoso de forma a problematizá-lo, refletindo sobre a ordem social estabelecida nele (e por ele). Para isso, definimos que seria interessante estudar com os alunos o conceito de estereótipos para, então, questioná-los, desconstruí-los e/ou conduzir novos significados a eles; daí o título deste trabalho: "Leitura e produção escrita de contos maravilhosos por uma perspectiva crítica”. Para além das características do gênero discursivo e das habilidades linguísticas que seriam enfocadas, o objetivo era incluir reflexões acerca dos valores (pré)concebidos e transmitidos socialmente, a fim de questionar visões de mundo, buscar sentidos que foram, ao longo do tempo, sedimentando-se nos contos e explicar por que isso pode ter ocorrido. Acreditamos que um trabalho crítico e transformador, de levantamento de questões e estímulo ao pensar, pode contribuir para a formação humana e cidadã dos alunos.

\section{FundamentaÇão teórica}

O embasamento teórico do projeto que envolveu os bolsistas do PIBID, alunos de graduação em Letras, levou em consideração as necessidades dos próprios graduandos, que seriam, de fato, os protagonistas das atividades. Conforme interagia com eles, observava pontos teóricos que deveriam ser pesquisados e estudados antes e durante o projeto para a realização de cada etapa com os alunos da educação básica. Em outros termos, foram definidos tópicos teóricos que seriam 
estudados e discutidos com os graduandos, para que pudessem desenvolver o trabalho com os alunos do fundamental.

Assim, este relato toma, como um dos pilares teóricos, o estudo sobre sequências didáticas apresentado por Tápias-Oliveira (2015), em que a autora discute procedimentos para aulas de leitura, questões de leitura trazidas pelos Parâmetros Curriculares Nacionais de Línguas - PCN e reflexões sobre a prática do professor para o trabalho com gêneros discursivos. $O$ passo a passo das sequências será apresentado no item "Descrição das sequências didáticas". Além das sequências didáticas estruturadas com base em Tápias-Oliveira (2015), também foram estudadas as sequências didáticas com base em DOLZ, NOVERRAZ e SCHNEUWLY (2004), que, basicamente, propõem o trabalho com as características ensináveis de um dado gênero para proporcionar aos alunos domínio da escrita e da leitura dele. $\mathrm{O}$ cerne desta proposta pedagógica é o trabalho com projetos que possibilitam uma recriação das condições de produção e circulação do gênero. A ideia era desenvolver as sequências didáticas referentes à leitura e à produção do gênero discursivo definido, a saber, contos maravilhosos, para a elaboração de um livro, que teria maior potencial de circulação social, o que daria, por sua vez, mais significação à aprendizagem.

Como norteador das práticas pedagógicas pensadas para as aulas, está o pensamento de Paulo Freire (2018) sobre a educação democrática e transformadora, que não vê o aluno como uma tábula rasa, desprovido de conhecimento ou com conhecimentos imprestáveis. Pelo contrário, concordamos com o pensamento freireano, segundo o qual a educação deve se afastar de uma concepção bancária, por meio da qual o professor, tido como detentor do saber, depositaria conhecimentos no aluno, o qual deverá, no dia da prova, mostrar que os aprendeu, como se o professor fosse "sacar" os resultados. A interação durante as sequências didáticas planejadas e desenvolvidas passam por uma gestão democrática, a fim de ouvir os alunos, observar seus conhecimentos prévios, propor desafios a eles a partir de seus contextos sociais, levá-los a fazer relações com o que já sabem e com o que podem aprender, enfim, as ações visam passar por um olhar dialógico, em que todos ensinam e aprendem. O professor atua, dessa forma, como mediador essencial do processo.

Este relato de experiência está ancorado, ainda, em Bakhtin (2003 e 2006), sobretudo em suas reflexões acerca da língua e linguagem, da dialogia intrínseca à enunciação e do próprio conceito de gênero discursivo. Como o gênero delimitado para o projeto foi o gênero conto maravilhoso, foram estudados os elementos 
essenciais para sua caracterização, leitura e produção. A fundamentação teórica principal pode ser subdividida nos itens que seguem.

\subsection{Questões Relacionadas Às ideias de Bakhtin}

O Círculo de Bakhtin atribuiu grande importância à linguagem e, para se compreender o desenvolvimento de suas ideias, três aspectos são fundamentais: a questão da unicidade e eventicidade do Ser, a contraposição eu/outro e o componente axiológico (valorativo) intrínseco ao ser humano. Segundo Faraco (2006), para Bakhtin, é preciso refletir sobre o homem concreto, sobre a linguagem como algo singular, um evento único e irrepetível. Quanto à contraposição eu/outro, o autor explica que, dentre os estudos bakhtinianos, o mundo em relação ao eu e ao outro ganha valores diferentes, ou seja, é significado e interpretado sob um quadro axiológico a partir do qual cada um orienta seus atos; logo, é no plano da alteridade que o sujeito atribui sentidos ao mundo ao seu redor. Faraco (2006) esclarece que, de acordo com esses postulados, viver é tomar posição axiológica, é posicionar-se em relação a valores, e vivemos em um mundo saturado de valores, no qual nossos atos são gestos axiologicamente responsivos. Nesse sentido, todo enunciado - ato de linguagem singular, irrepetível, concretamente situado e atitude responsiva - não pode ser neutro, pois emerge necessariamente de um contexto cultural já saturado de valores sócio-históricos.

Outro ponto importante da teoria bakhtiniana é que a linguagem é vista não apenas por uma perspectiva linguística, que é relevante, mas insuficiente por enfocar o enunciado exclusivamente como um fenômeno da língua, desvinculado do contexto material e situado de realização. A linguagem, apenas pela perspectiva linguística, é indiferente às dimensões axiológicas. Para Bakhtin (2006), a palavra, signo linguístico, tem seu aspecto concreto-palpável (morfossintático e fonológico), seu aspecto semântico e seu aspecto axiológico (tom avaliativo). Logo, uma leitura verdadeiramente crítica precisa ir além do aspecto linguístico dos signos, além da gramática tradicional e suas nomenclaturas e compreender o enunciado em todo o seu contexto produzido e recebido, que é sempre saturado por valores.

Ao ato de interação enunciativa, é inerente a dialogia, processo pelo qual cada enunciado é uma resposta ativa a outro que o antecede e provoca outros que o sucederão. $\mathrm{O}$ enunciado é social, ou seja, reflete e refrata valores sócio-historicamente construídos; ele é uma réplica ao já-dito e também provoca uma réplica a ser dita 
(já solicitada e prevista), e essa rede de discursos que respondem a outros e possibilitam outros configura o fenômeno do dialogismo (BAKHTIN, 2006).

A dialogia não é um ato passivo, um mero reconhecimento, mas uma resposta ativa que significa uma tomada de decisão diante do enunciado. Nesse sentido, ler criticamente é assumir esse jogo dialógico de forma ativa. Para haver dialogia, o material linguístico precisa ser observado na esfera do discurso, ou seja, ser transformado em enunciado concreto, no qual se assume a posição de um sujeito social, capaz de fazer réplicas ao dito, confrontar posições, concordar com a palavra do outro, discordar dela, confirmá-la, ampliá-la. Para tanto, o conhecimento por si só da nomenclatura gramatical não é suficiente para que se compreenda os enunciados em seu processo dialógico e se assuma uma posição valorativa diante deles.

Essas réplicas discursivas consistem, basicamente, em gêneros discursivos, os quais, segundo Bakhtin (2003), são o produto da atividade humana e o meio pelo qual ela ocorre. São enunciados concretos constituídos de signos verbais e/ou não verbais. Apresentam como características que os diferenciam uns dos outros: conteúdo temático, organização composicional e estilo, aspectos condicionados às suas condições de produção e circulação e às finalidades a que se propõem. Os gêneros são relativamente estáveis e podem ser primários (cotidianos) ou secundários (mais complexos, empregados em situações de comunicação mais elaboradas). Uma pessoa pode dominar muito bem a língua em relação à gramática e ao vocabulário, mas pode não saber se comunicar em dada situação, porque talvez não domine o repertório de gêneros daquela prática social.

A tradição escolar, apesar de inúmeros avanços para uma educação mais significativa, ainda apresenta práticas muitas vezes ancoradas no ensino da nomenclatura gramatical. $O$ ensino da leitura por meio de gêneros do discurso, por exemplo, levando em conta suas características e sua essência dialógica, pode contribuir para a reflexão sobre a língua de forma descritiva, analítica, crítica, diferente de um ensino baseado na gramática normativa, impondo regras descontextualizadas e excludentes. Uma das pesquisadoras que discutem essa questão é Goldstein, em algumas publicações, como no artigo "Gêneros do discurso e gramática no ensino de língua materna" (2009), em que apresenta exemplos de trabalho com análise linguística a partir do enunciado concreto. 


\subsection{QUeStões RELACIONAdAS AO GÊNERO CONTO MARAVILHOSO}

Após discussões gerais das ideias de Bakhtin com os estagiários, começou-se a investigar as especificidades do gênero conto maravilhoso. Eles compilaram muitas informações e as estudaram. Tiveram acesso a alguns materiais desenvolvidos e disponíveis pelo Projeto Observatório/UNITAU ${ }^{3}$, nos quais constavam conhecimentos desejáveis acerca do gênero em questão. Comentei com os bolsistas que todo professor precisa entrar em sala de aula munido de conhecimentos teóricos acerca do tópico alvo do processo de ensino-aprendizagem e precisa ter planejado bem suas aulas, as quais, mesmo que não sigam à risca o planejamento, foram pensadas e poderão ser bem (re)conduzidas.

Ficou definido, portanto, que nos primeiros contatos com os alunos do ensino fundamental, quando ainda se discutem aspectos de produção e circulação do gênero, os estagiários fariam uma discussão em sala para o levantamento de conhecimentos prévios e compartilhamento de informações e, ao final, distribuiriam uma pequena folha com o seguinte texto, no qual haviam compilado um resumo geral sobre o gênero em questão:

\section{Contos maravilhosos}

Os contos maravilhosos são histórias antigas que escapam à realidade: um mundo de faz de conta, com bruxas, fadas, objetos que se movem, animais e monstros falantes que convivem com os seres humanos. Essas histórias sempre se passam "há muito tempo atrás", "em um lugar muito distante", para dar a ideia do desconhecido e do fascinante. O personagem principal, o protagonista, é quase sempre o bonzinho, que vive tranquilo seu cotidiano até que aparece seu antagonista, que é mau e que insiste em causar-lhe problemas aparentemente insuperáveis. Mas o herói da história sempre arranja uma forma de solucionar esses problemas: ele pode usar de sua esperteza; pedir ajuda; achar um objeto ou personagem mágico que lhe ajude (chave mágica, varinha de condão, fadas); e então, tudo volta ao normal, os bonzinhos saem sãos e salvos.

Essas histórias serviam para várias coisas: para entretenimento das crianças, para o conhecimento das dificuldades da vida (a dor, o castigo, a injustiça, a perda, o mundo externo à nossa casa, o abandono, a morte) e como superá-las.

3. Projeto Observatório/UNITAU 2011 - 2014 - "Competências e habilidades de leitura: da reflexão teórica ao

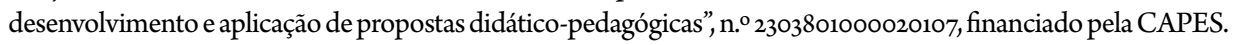


Essas narrativas também costumam seguir sempre um padrão de acontecimentos, havendo um início (quando tudo ainda está na normalidade), um conflito (quando algo muda, algo inesperado acontece ou surge um problema ou questão), um clímax (quando ocorre uma tensão entre o protagonista e o antagonista acerca desse problema) e o desfecho (quando tudo é resolvido).

Nelas também há a presença de muitos estereótipos: a princesa (a menina/mulher ideal); o príncipe (o cavalheiro, educado, gentil, valente); a bruxa (feia e má); a madrasta (egoísta, má e injusta); as crianças (inocentes, brincalhonas ou bagunceiras); a mãe e a avó (muito gentis, amáveis e preocupadas); entre outros.

Esse texto seria lido em conjunto, com a sala, fazendo-se pausas para explicações e exemplificações de, por exemplo, "conflito", “clímax", “estereótipos”.

Em seguida, foram planejadas as sequências didáticas, de modo que os estagiários percebessem o encaminhamento didático dos processos de leitura. Construímos dois módulos, um de leitura e outro de produção escrita, que são relatados adiante.

\section{DESCRIÇÃO DAS SEQUÊNCIAS DIDÁtiCAS}

Como comentado, observei a necessidade de se estudar com os estagiários/ bolsistas do PIBID o gênero conto maravilhoso, de modo que compreendessem as condições de produção e circulação desse gênero, bem como os aspectos composicionais, o estilo da linguagem, os propósitos comunicativos, enfim, elementos importantes que caracterizam esse tipo de conto. Dessa forma, estabeleci que, nos dois dias em que permanecessem na escola, estudariam sobre o gênero proposto, em livros, artigos, sites na internet, isto é, em variados suportes pelos quais obtivessem informações e as confrontassem. Nesses dias, deveriam permanecer na biblioteca da escola, onde havia livros e acesso à internet. Nas aulas vagas, encontrava-me com eles para discutir o que haviam pesquisado.

Percebi, porém, que pouco conheciam acerca da teoria dos gêneros, das ideias de Bakhtin, de aspectos teóricos fundamentais para que compreendessem a essência do ensino por meio de gêneros. Desenvolvi com os estagiários uma espécie de grupo de estudos, visando entender a concepção de linguagem em Bakhtin (2006), o conceito de gênero discursivo (BAKHTIN, 2003) e o funcionamento de sequências didáticas (TÁPIAS-OLIVIERA, 2015; DOLZ, NOVERRAZ e SCHNEUWLY, 
2004) para, a partir disso, esboçarmos os procedimentos que seriam feitos com os alunos de $6^{\circ}$ ano que nos esperavam.

Concomitantemente aos estudos voltados à teoria de base do projeto, planejávamos as sequências didáticas a serem realizadas nas classes selecionadas. As sequências didáticas de leitura e escrita de contos maravilhosos modernos ${ }^{4}$ foram descritas e desenvolvidas da seguinte forma:

\section{- Objetivo e Justificativa}

Trabalhar com contos maravilhosos e suas características é orientação dos Parâmetros Curriculares Nacionais de Língua Portuguesa referentes ao ensino fundamental II (BRASIL, 1998). Nesse sentido, o projeto objetivou desenvolver nos alunos habilidades de leitura e de produção escrita, a partir de um gênero narrativo importante, mas que, muitas vezes, contribui para a manutenção de estereótipos, tais como o de princesa frágil e bela (ideia de que mulher é frágil, tem que ser magra, loira, vivendo à espera de um marido que viria em um cavalo branco), a madrasta má, a fada boa etc. Esses estereótipos podem constituir preconceitos sociais, e essas questões podem ser discutidas com os alunos, de forma que eles passem a refletir mais criticamente sobre a sociedade circundante, praticando ações mais inclusivas.

\section{- Procedimentos didáticos: etapa de leitura de contos MARAVILHOSOS}

A. Condições de produção e circulação do gênero "conto maravilhoso": exploração e ampliação do conhecimento prévio dos alunos acerca dos contos tradicionais. Após diálogo com os alunos e explicações gerais, fazer as seguintes perguntas (respostas apenas orais):

- O que são contos maravilhosos? Em que época começaram a ser produzidos? Com que finalidade?

4. O termo "modernos" desvenda nosso objetivo pontuado, de reflexão e produção de novos sentidos para os contos, respeitando as diferenças humanas e sociais. Inúmeros filmes contemporâneos revelam essa perspectiva, como "Deu a louca na Chapeuzinho", "Shrek”, "Malévola”, entre outros, em que a noção de amor, de beleza, de justiça... a visão de velhice, de casamento, de família, de realeza etc. são questionados e ressignificados. A ideia não é descartar um sentido em prol de outro, mas instigar nos alunos o potencial reflexivo e questionador sobre aquilo que parece naturalmente estabelecido. 
- Quem os produz?

- Por que alguém os escreve? Quais intenções?

- Quem lê conto maravilhoso? Por quê?

- Quais características são próprias do conto maravilhoso?

- Onde podemos ler um conto maravilhoso?

Após essas perguntas, entregar uma folha com a síntese de informações gerais sobre o gênero conto maravilhoso.

B. Leitura global com apresentação de um conto escolhido (Ex: A princesa e a ervilha; Senhora Holle). As perguntas seguintes podem servir de roteiro inicial para a leitura global, de exploração anterior à leitura integral.

- Qual é o título? Qual será o provável assunto da história? O que será que vai acontecer?

- Olhem a ilustração: o que pode ter acontecido?

- Quem é o autor? Vocês o conhecem?

No decorrer da leitura global, os alunos levantarão hipóteses de leitura que deverão ser confirmadas ou descartadas durante a leitura propriamente dita. A partir das hipóteses levantadas, formular um objetivo de leitura que guiará o olhar do leitor na primeira leitura, que seguirá a leitura global. Por exemplo: se o conto é "A princesa e a ervilha", um objetivo de leitura, a partir do título, poderá ser: no título, geralmente aparece algo central na história; logo, qual será a relação da princesa com a ervilha?

C. Leitura detalhada do conto (elaboração de algumas perguntas sobre estrutura da narrativa: início, conflito, clímax e desfecho; e sobre os elementos da narrativa: personagens, narrador, tempo, espaço etc.; também poderão ser feitas algumas perguntas pertinentes para inferência do significado de uma palavra, para compreensão do tom do narrador ou das emoções suscitadas, para compreensão de ironias ou de outros aspectos, inclusive, linguísticos).

D. Leitura crítica: neste momento, refletir sobre o conceito de estereótipos e de valores sociais (basicamente de visões do que seria certo ou errado, de acordo com a sociedade e a cultura, dialogando sobre como essas visões foram sedimentadas, em favor de quê e como poderiam ser transformadas); com esses 
conceitos em mente, passar a discuti-los no texto. Pode-se fazer a repetição desses procedimentos com outros contos maravilhosos tradicionais escolhidos (Ex: Chapeuzinho Vermelho, Bela Adormecida, O patinho feio etc.). Para fazer as escolhas, coletar informações sobre o conhecimento prévio dos alunos, a fim de identificar quais leituras já realizaram ou não.

E. Apresentação de um conto maravilhoso moderno para as mesmas etapas anteriores:

- Leitura global do conto, levantamento de hipóteses de leitura e estabelecimento de objetivo de leitura, que pode ser: "Leiam o conto e tentem observar quais elementos têm a ver com a nossa época";

- Leitura detalhada do conto (exploração da estrutura e dos elementos narrativos);

- Leitura crítica (discussão sobre a desconstrução dos estereótipos, observando novos valores da sociedade ou outras possibilidades de compreender atitudes).

Pode-se repensar o procedimento com outros contos maravilhosos modernos (levar cópias impressas aos alunos).

F. Etapa da apresentação de um filme aos alunos, em que a desconstrução de aspectos tradicionais ocorra. Há vários exemplos atualmente, como "Malévola", "Deu a louca na Chapeuzinho", "Valente", "Como treinar seu dragão" etc. Também nesta etapa, poderá ocorrer a solicitação de um texto (livre) em que os alunos discutam o que observaram no filme sobre estereótipos e valores (essa proposta deverá ser feita aos alunos antes do filme, para que eles tenham um objetivo de leitura).

- Procedimentos didáticos: etapa da produção escrita de CONTOS MARAVILHOSOS (RESERVAR UM DIA, COM DUAS AULAS, PARA QUE OS ALUNOS INICIEM AS PRODUÇÕES)

A. Planejamento do enredo (os alunos vão responder a estas perguntas primeiramente, que servirão de planejamento de texto):

- Qual será o conto tradicional que vou reescrever de forma modernizada?

5. Junto aos alunos do PIBID, ressaltamos a importância de planejamento para o texto escrito, seguido de um possível rascunho. A ideia de trabalho planejado em escrita contribui para a desmistificação do ato de escrever como dom, puro talento e inspiração que apenas poucos teriam. Todo aluno é capaz de criar seu texto, por meio de método, planejamento, estudo, tentativas, auxílio docente etc. 
- Que valores/visões sobre o mundo e as pessoas quero discutir no meu texto?

- Que estereótipos irei criticar / modificar / desconstruir / ironizar / reforçar?

- Quais serão as personagens da minha história e quais características terão? Quem será o protagonista? E o antagonista?

- Quais elementos do conto maravilhoso vou explorar? Haverá fadas, bruxas, feitiços (que são elementos típicos desse gênero)?

- Como será o cenário da minha história?

- Qual será o conflito do conto?

- Como será o clímax?

- Como será o desfecho?

B. Após pensar nessas questões de A e respondê-las brevemente, solicitar a escrita da primeira versão do conto maravilhoso.

C. Correção da primeira versão (enquanto isso, os alunos podem ilustrar os seus contos).

D. Primeira devolutiva e reescrita.

E. Segunda correção.

F. Segunda reescrita para casos necessários e início da digitação dos textos.

G. Digitação e organização do livro (textos e ilustrações).

\section{- Conclusão do projeto}

O produto final do projeto pode ser um livro de contos maravilhosos modernos a ser exposto na feira da escola. É ideal produzir um exemplar de livro para cada aluno e um para o acervo da biblioteca.

\section{- Duração do projeto}

Ao todo, as atividades são previstas para serem realizadas em 20 aulas de 50 minutos cada, aproximadamente.

\section{- Materiais}

Alguns materiais são previstos: cópias de contos maravilhosos e exercícios; livros para leitura; DVD do filme escolhido; computador para digitação dos contos; folhas sulfites e impressora para impressão dos livros de contos. 


\section{Avaliação dos resultados das etapas efetivadas}

A etapa da leitura prevista nas sequências didáticas foi cumprida com êxito, embora o tempo não tivesse permitido trabalho com muitos exemplares de contos. Já a etapa da produção escrita não foi totalmente executada, o que prejudicou as etapas finais, de confecção e exposição do livro de contos maravilhosos modernos. A gestão do tempo sofreu interferências do período de provas mensais que, segundo normas institucionais a que somos submetidos, deveriam ser aplicadas aos alunos e interferências de problemas que os próprios estagiários enfrentaram, como dificuldades particulares de chegarem à escola, o que prejudicava a aula prevista em determinados dias. Além disso, ocorreu pequena mudança no quadro de estagiários participantes do projeto, tendo em vista que o programa PIBID atendia, na ocasião, a quatro escolas da cidade no total. Chegamos, portanto, apenas à etapa da produção escrita, primeira correção e devolutiva. Não foram possíveis as etapas de reescrita, ilustração, segunda (e até terceira) correção, digitação, confecção do livro e sua exposição.

Os estagiários-bolsistas tiveram a experiência de ministrar aulas. Atuando como supervisora do PIBID e também como professora dos estagiários e dos alunos do ensino fundamental, eu ficava na sala acompanhado o andamento das atividades. Após cada aula lecionada, conversava com os bolsistas, apontando-lhes os pontos positivos e negativos observados. Isso certamente contribuiu muito para a formação docente deles, além de compreenderem que, embora seja essencial o planejamento didático, muitos fatores no contexto escolar fogem ao controle do professor, que precisa, portanto, rever seus planos a fim de melhor atender às necessidades de seus alunos.

Cada aula era lecionada por um estagiário que contava com o apoio de outro, ou seja, havia dois estagiários por aula. Desafios surgiram, como a gestão do tempo das atividades. Por exemplo, nas primeiras aulas, os alunos das classes selecionadas fizeram as atividades propostas de modo muito rápido, e os estagiários ficaram sem ter o que trabalhar com eles. Nesse momento, assumi a aula e, depois, expliquei aos estagiários que todo professor deve estar preparado para imprevistos como esse, apresentando outra atividade para aproveitamento do tempo. Em determinados momentos, também houve dificuldades de explicar um ou outro tópico ou de solucionar uma situação de indisciplina, ocasião em que pude auxiliar os futuros docentes. Pôde-se perceber que tanto estagiários como alunos puderam aprender mais durante as atividades.

Essa experiência foi muito valiosa também para minha própria formação docente. Eu, como professora do curso de Letras, lecionava acerca de conteúdos da língua 
portuguesa previstos nos currículos das disciplinas da graduação, buscando, principalmente, levar os alunos universitários, futuros professores, a refletirem sobre a transposição didática desses conteúdos, sobre as situações de sala de aula, sobre a conduta do professor etc. Em muitos momentos de aula, discutia com os graduandos acerca das características dos alunos do ensino básico, suas necessidades, as dificuldades que surgiam no contexto escolar, sempre pontuando minhas próprias experiências. Assim, quando recebi os estagiários na escola onde também lecionava para o ensino fundamental, minha função como formadora de professores se tornou ainda mais importante para mim, pois precisava fazer pontes entre teoria (que estudávamos na graduação) e prática (que era materializada no ensino básico), além de demonstrar coerência ética de prática docente e educação democrática - não apenas em relação ao domínio técnico, mas, sobretudo, em relação à interação com os alunos e ao convívio com eles.

Embora não tenhamos conseguido cumprir todos os procedimentos previstos nas sequências didáticas, fiquei muito satisfeita com o avanço dos alunos do ensino fundamental a respeito da compreensão dos textos e da criticidade com que passaram a discuti-los, questionando e desconstruindo estereótipos; e também com os alunos graduandos, que se empenharam nas aulas, preocuparam-se com os resultados e engajaram-se em sua própria formação, que precisa sempre estar em mutação, reflexão e avanço.

\section{CONSIDERAÇÕES Finais}

A experiência docente vivida e relatada aponta para a importância de projetos institucionais e programas governamentais como o PIBID, para a busca de formação de qualidade para novos professores. Esse programa oferece bolsa (auxílio financeiro fundamental para o acesso e a permanência de graduandos de baixa renda no ensino superior), tempo, ambiente apropriado e supervisão de um profissional mais experiente, no próprio contexto da prática, voltados àqueles que estão em fase de formação inicial. Esses elementos fazem diferença para a atuação profissional mais consistente após a saída da universidade. Além disso, os alunos do ensino fundamental que têm contato com os graduandos/bolsistas podem contar com o apoio mais próximo e direcionado durante as aulas, apoio este que fica, por vezes, impossibilitado de ser oferecido pelo professor regular devido à quantidade de alunos de uma sala de aula e do tempo limitado para o desenvolvimento das atividades. 
Logo, os benefícios são mútuos: para o graduando do ensino superior e para o aluno do ensino fundamental; ambos podem interagir, aprender e ensinar.

Para finalizar, quero salientar a importância dessa experiência para minha própria formação como professora de diferentes níveis acadêmicos. As reflexões passam pela necessidade de se pensar na coerência e na relação inerente entre teoria e prática, além do engajamento ético e político que deve existir no processo de ensino e aprendizagem (FREIRE, 2018).

\section{REFERÊNCIAS}

BAKHTIN, M. Estética da criação verbal. Trad. Paulo Bezerra. 4. ed. São Paulo: Martins Fontes, 2003. BAKHTIN, M. Marxismo e Filosofia da linguagem. 12. ed. São Paulo: HUCITEC, 2006.

BRASIL. Secretaria de Educação Fundamental. Parâmetros Curriculares Nacionais: terceiro e quarto ciclos do ensino fundamental: língua portuguesa. Brasília: MEC/SEF, 1998.

GOLDSTEIN, N. S. Gêneros do discurso e gramática no ensino de língua materna. Revista SCRIPTA, Belo Horizonte, v. 13, n. 24, p. 95-109, $1^{\circ}$ sem. 2009.

DOLZ, Joaquim; NOVERRAZ, Michele; SCHNEUWLY, Bernard. Sequências didáticas para o oral e a escrita: apresentação de um procedimento. In: SCHNEUWLY, B.; DOLZ, J. Gêneros orais e escritos na escola. Campinas: Mercado de Letras, 2004. p. 95-128.

FARACO, Carlos Alberto. Linguagem e Diálogo: as ideias linguísticas do círculo de Bakhtin. 2. ed. Criar Edições: Curitiba, 2006.

FREIRE, Paulo. Pedagogia da autonomia: saberes necessários à prática educativa. 57. ed. São Paulo: Paz e Terra, 2018.

TÁPIAS-OLIVEIRA, Eveline M. (Org.). Reflexões sobre aulas de leitura, PCN de línguas e prática do professor. Taubaté, SP: Editora Universitária da Universidade de Taubaté; Editora e Livraria Cabral Universitária, 2015.

\section{SOBRe A AUTORA}

Viviane Dinês de Oliveira Ribeiro Bartho, especialista em Leitura e Produção de Textos; Mestra em Linguística Aplicada; Doutora em Letras; Professora efetiva de português do Instituto Federal de São Paulo, campus de Campos do Jordão. E-mail:viviane_dines@yahoo.com.br; viviane.bartho@ifsp.edu.br.

Recebido em 13 de maio de 2019 e aprovado em o7 de julho de 2020. 